\title{
An Evaluative Study To Assess Effectiveness Of Educational Package Regarding Well Being Behavior Among Adolescents In Selected Rural And Urban Areas At Aburoad In Sirohi District.
}

\author{
Mr. Kalpesh Kumar \\ ${ }^{*}$ PH.D. Scholar (Maharaja Vinayaka Global University Jaipur ), M.Sc. Nursing( Medical -Surgical Nursing), Principal ,Vidhyadeep Institute of \\ Nursing, Anita (Kim ), Dist -Surat (Gujarat) 394110 \\ DOI: 10.29322/IJSRP.11.08.2021.p11652 \\ http://dx.doi.org/10.29322/IJSRP.11.08.2021.p11652
}

\begin{abstract}
Adolescence has been considered as a period marked with identity crisis. The adolescent crisis of ego identity versus role confusion, when resolved, enables individuals to integrate all the images about oneself into a personal identity and consolidate various roles one has to play. As part of one's overall health, mental and emotional health or well being is a necessary condition to enable one to manage one's life successfully.
\end{abstract}

Index Terms- Evaluative, Educational package, Well being behavior, Adolescence, Rural area, Urban Area,

\section{INTRODUCTION AND NEED OF STUDY}

$\mathrm{W}$ ell-being is a positive outcome that is meaningful for people and for many sectors of society, because it tells us that people perceive that their lives are going well.

Good living conditions (e.g., housing, employment) are fundamental to well-being. Tracking these conditions is important for public policy. However, many indicators that measure living conditions fail to measure what people think and feel about their lives, such as the quality of their relationships, their positive emotions and resilience, the realization of their potential, or their overall satisfaction with life-i.e., their "well-being." Well-being generally includes global judgments of life satisfaction and feelings ranging from depression to joy .

Well-being, welfare or wellness is a general term for the condition of an individual or group, for example their social, economic, psychological, spiritual or medical state; a high level of well-being means in some sense the individual or group's experience is positive, while low well-being is associated with negative happenings.

Adolescence is defined by WHO as, "the age group of 10-19 years". In India, adolescents constitute 21.4 percent of the population, comprising one fifth of the total population. Adolescence is the transitional stage of development between childhood and adulthood, representing the period of time during which a person experiences a variety of biological changes and encounters a number of emotional issues.

Adolescents are particularly at high risk of unintentional injuries, violence, early pregnancy, sexually transmitted infection, and abuse of tobacco, drugs and alcohol. Promoting healthy choices among adolescents can help them be healthy and productive into adulthood.

One of the most obvious changes during this time is puberty. Boys' and girls' bodies begin to change and adolescents have to adjust to their physical development. This physical change often coincides with entry into new schools with larger social networks Most adolescents are good citizens who are physically, psychologically and socially healthy. A vast majority are free of major mental, behavioral or addictive disorder, an increasing percentage are volunteering in their communities, and fewer are involved in school violence, and other forms of behavioral disorders. Despite these facts, adolescence is far from being a placid period. Adolescence is, in fact, a time of change and risk ${ }^{4}$. One of the most obvious changes during this time is puberty. Boys' and girls' bodies begin to change and adolescents have to adjust to their physical development. This physical change often coincides with entry into new schools with larger social networks 5 .

\section{OBJeCtIVES}

1. To assess the well being behavior among adolescent in rural area as measured by structured questionnaire.

2. To assess the well being behavior among adolescent in urban area as measured by structured questionnaire.

3. To compare the well being behavior among adolescent in rural area as measured by structured questionnaire.

4. To evaluate the effectiveness of educational package on well being behavior among adolescent in rural and urban area.

Hypothesis :- A hypothesis is usually considered as the principle instrument in research. Hence, it is a statement of the predicted relationship between two or more variables in a research study ${ }^{18}$ 
The hypotheses will be tested at 0.05 level of significance

The hypotheses will be tested at 0.05 level of significance

$\mathbf{H}_{1}$ : The mean post test knowledge score of adolescence on well being behavior in adolescence will be significantly higher than that of their mean pre test knowledge scores.

$\mathbf{H}_{2}$ : There will be a significant association between pre-test level of knowledge on well being behavior in adolescence among the adolescence and with their selected demographic variable.

H3: There will be no significant difference between the well being behavior in adolescence of rural and urban area.

\section{CONCEPTUAL FRAME WORK}

According to Polit and Hungles (1995) "conceptual frame work represent a less formal attempt at organizing phenomenon than theory and deal with abstractions that are assembled by virtue of their relevance to a common theme".

Conceptual frame work represent a less formal attempt at organizing phenomenon than theory and deal with abstractions that are assembled by virtue of their relevance to a common theme

Conceptualization is the process of forming ideas, design, and plans. A conceptual framework deals with concepts assembled together by virtue of their relevance to the research problem, which provides a certain frame of reference for clinical practices, research and education. It gives direction for planning research, design , data collection and interpretation of findings.

\section{REVIEW OF LITERATURE}

Descriptive study was examined on the psychosocial wellbeing of children in the family of abused partners. The study sample was 500 randomly drawn from five local government areas of Ibadan metropolis. "Family Violence and Psychosocial WellBeing of Children's Evaluative Questionnaire (FVPSWBOCEQ)" was used to collect the requisite data. The result showed that there was a significant relationship between Family violence variables as promiscuity, infidelity and physical assault and psychosocial well-being of children in the family of abused partners. While religion and coercive sex of abused partners have no significant relationship with psychosocial well-being of child.

According Shamokin and Ryff (2002) psychological wellbeing entails perception of engagement with existential challenge in life.Ryff1995 and coworkers constructed six key dimension of psychological well being. Self acceptance, positive relation with other people, autonomy, environmental mastery and personal growth.

A concordant descriptive study was conducted on the prevalence of mental and adolescent disorders in Goa. A total of 2684 of children were recruited from six urban wards and four communities. All were interviewed on issues affecting socioeconomic, educational, neighborhood and parent relationships. The findings showed that according to DSM IV $1.8 \%$ of adolescents with mental health problems. The most common were $1 \%$ anxiety and $0.5 \%$ depression problems. This emphasizes the importance of protective factors in the mental and emotional wellbeing of the individual.
A study of 251 and 250 boys from grades nine to 12 in two urban and rural high schools found that mental health and socioeconomic status were positive. I also examined the connection between family functioning and adolescent mental health and research adjustment showed that family functioning and family relationships have a positive impact on well-being and rehabilitation for young people.

The study was evaluated against a school-based adjustment of 60 rural youth in terms of their emotional, social and educational fields. The sample consisted of 30 boys and 30 girls between the ages of 14-16, studying in grades 8th to 10th at a public-private partnership school. A school adjustment list compiled by Sinha and Singh (1984) modified by an investigator was used for data collection. They reported significant differences in gender balance where boys were better off, and no significant difference was seen in school, social and educational.

Longitudinal studies have shown that adolescents who are depressed among adolescents between the ages of 14-16 were at greater risk of adverse psychological effects in adolescence and adulthood (16-21 years). Data were collected during a 21-year long-term study of the birth of 1265 children. Measures include the DSM-III-R high stress test (age 14-16); mental disorders, academic achievements, and social functioning (ages 16-21); social, family and individual aspects; and disruption of cooperation. The results showed that thirteen percent $(13 \%)$ of the group grew depressed between the ages of 14 and 16. Young people with adolescent depression were more likely $(\mathrm{P}<.05)$ an increased risk of future major depression, anxiety disorders, nicotine dependence, alcohol or alcohol dependence, suicide attempts, academic poor performance, unemployment, and early parenting. These organizations were like girls and boys. The results suggested the existence of 2 major mechanisms linking previous stress with subsequent outcomes. First, there was a direct link between previous depression and an increased risk of major post-traumatic stress disorder or anxiety disorder. Second, associations between initial stress and other outcomes were defined by the presence of social, family and individual disruptions. So young people with initial stress were present

A concordant descriptive study was conducted on the prevalence of mental and adolescent disorders in Goa. A total of 2684 of children were recruited from six urban wards and four communities. All were interviewed on issues affecting socioeconomic, educational, neighborhood and parent relationships. The findings showed that according to DSM IV $1.8 \%$ of adolescents with mental health problems. The most common were $1 \%$ anxiety and $0.5 \%$ depression problems. This emphasizes the importance of protective factors in the mental and emotional wellbeing of the individual.

A study of 251 and 250 boys from grades nine to 12 in two urban and rural high schools found that mental health and socioeconomic status were positive. I also examined the connection between family functioning and adolescent mental health and research adjustment showed that family functioning and family relationships have a positive impact on well-being and rehabilitation for young people.

The study was evaluated against a school-based adjustment of 60 rural youth in terms of their emotional, social and educational fields. The sample consisted of 30 boys and 30 girls between the ages of 14-16, studying in grades 8th to 10th at a 
public-private partnership school. A school adjustment list compiled by Sinha and Singh (1984) modified by an investigator was used for data collection. They reported significant differences in gender balance where boys were better off, and no significant difference was seen in school, social and educational.

\section{RESEARCH Methodology:-}

Pre experimental one group pre-test post-test design with evaluative approach was adopted to accomplish the objectives of the study. A sample of 300 adolescence was selected for the study by using purposive sampling technique. An educational package was prepared by the investigator focusing on the well being behavior. Pre-test was conducted by administering a structured knowledge questionnaire followed by the administration of the educational package. After 7 days a post-test was conducted by using the same questionnaire to assess effectiveness of educational package.

\section{Research approach}

Research approach indicates the basic procedure for conducting the study. The selection of approach depends upon the purpose of the study. Evaluative approach is an applied form of research that deals with the question how well the programme is meeting its objective. Its goal is to assess or evaluate the success of a programme. An evaluative approach is the process of collecting and analyzing information relating to the functioning of a programme, policy or procedure in order to assist decisionmakers in choosing a course of action.

Change is a feature of the process that is observable and measurable as output, which should be different from that which is entered in the system that is input. In the present study, the output measures the gain in knowledge by comparing the mean post- test scores with mean pre-test scores.

The two group pre-test post-test design:

\begin{tabular}{|l|l|l|l|}
\hline Subjects & $\begin{array}{l}\text { Pre-test } \\
\left(\mathbf{1}^{\text {st }} \text { day }\right)\end{array}$ & $\begin{array}{l}\text { Treatment } \\
\left(\mathbf{1}^{\text {st }} \text { day }\right)\end{array}$ & $\begin{array}{l}\text { Post-test } \\
\left(\mathbf{7}^{\text {th }} \text { day }\right)\end{array}$ \\
\hline Adolescence (rural) & $\mathrm{OR}_{1}$ & $\mathrm{X}$ & $\mathrm{OR}_{2}$ \\
\hline Adolescence (Urban) & $\mathrm{OU}_{1}$ & $\mathrm{X}$ & $\mathrm{OU}_{2}$ \\
\hline
\end{tabular}

This two group pre test post test can be dramatically represented as

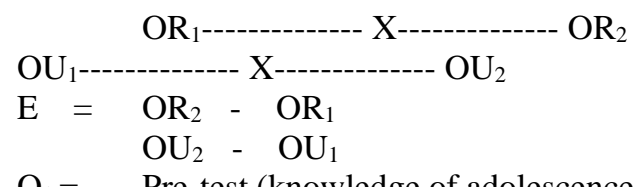

$\mathrm{O}_{1}=\quad$ Pre-test (knowledge of adolescence regarding well being behavior)

$\mathrm{R}=\quad$ Rural area $\quad \mathrm{U}=$ Urban area

$\mathrm{X}=$ Treatment (educational package to adolescence on well being behavior)

$\mathrm{O}_{2}=$ Post-test (knowledge of adolescence regarding well being behavior ).

$\mathrm{E}=\quad$ Effectiveness of educational package

The study design shows that on the first day, after explaining the purpose of the study to the samples, the investigator introduced himself to the subjects and obtained the informed consent after assuring confidentiality. Pre-test was conducted to collect the data by a structured knowledge questionnaire. On the same day, after the pre-test a educational package on well being behavior was administered. Seventh day of educational package post-test was conducted with the same questionnaire and improvement of knowledge on well being behavior in adolescence was assessed.

\section{RESULT}

The research approach for this study was evaluative in nature. One group pretest post test design was adopted in order to achieve the objectives of this study. The sample of 300 adolescence in selected rural and urban area in aburoad in sirohi district . Purposive sampling was used for the selection of sample. The instrument for the data collection was a structured interview questionnaire. It had two parts. Part I consisted of demographic data and part II consisted 40 items to assess the knowledge regarding well being behavior.

The experts established the content validity of the tool and educational package. The tool was found to be reliable and valid. The reliability of the tool was done by using the Karl Pearson's correlation formula. Spearman Browns formula was used to find out the reliability of the full test. The reliability of the tool was ' $r$ ' $=$ 0.84 , which indicated the tool was reliable.

Pilot study was conducted on ten adolescence from selected rural and urban area in aburoad in sirohi district. This gave the basis for the investigator to conduct the main study. The main study was conducted on 300 adolescence from selected rural and urban area in aburoad in sirohi district. Pre-test was conducted by structured knowledge questionnaire followed by administration of educational package. After 7 days post-test was conducted using the same questionnaire. The data obtained were analysed by using descriptive and inferential statistics.

\section{Major findings.:}

Calculated over all mean knowledge score of adolescents in pretest is 14.33 with 1.33 standard deviation, whereas mean Knowledge score and S.D. in post test is 30.3 and 9.5 subsequently.

Mean difference in pretest and post test 15.97. Calculated $t$ value is 28.83 which is more than tabled value at the degree of freedom 598. Calculated $\mathrm{p}(.0001)$ is less than established value .05 the researcher reject null hypothesis $\mathrm{H} 0$ and accept research hypothesis $\mathrm{H} 1$ that There is significant difference between the 
pre- and post-test knowledge scores of adolescents regarding wellbeing behaviour in selected rural and urban area

\section{CONCLUSION}

There was significant increase in the knowledge of adolescence after the administration of the educational package. Therefore, it was concluded that the educational package was effective in improving the knowledge foe adolescent age groups.

\section{REFERENCES AND BIBLIOGRAPHY}

[1] D.A. Dadhania. Mental Health and Psychological Well-being in Adolescence Boys and Girls. IJPMN, Volume 2, Issue 3, December-2015 ; 10-12

[2] The world health report 2001 - Mental Health: New Understanding, New Hope"(PDF). WHO. Retrieved 4 May 2014.

[3] Wellbeing concept Health related quality of life, Center for Disease Control and Prevention, http://www.ijcm.org.in/article.asp

[4] Published by Elsevier, a division of Reed Elsevier India, Pvt. Ltd on behalf of INDIACLEN

[5] Shaffer, D., Fisher, P., Dulcan, M. K., Davies, M., Piacentini, J., SchwabStone, M. E., Lahey, B. B., Bourdon, K., Jensen, P. S., Bird, H. R., Canino, G., \& Regiser, D. A. The NIMH Diagnostic Interview Schedule for Children Version 2.3: Description, acceptability, prevalence rates, and performance in the MECA Study. Methods for the Epidemiology of Child and Adolescent Mental Disorders Study. Journal of the American Academy of Child and Adolescent Psychiatry.1996:35; 865-877.

[6] Promoting Well-being Among America's Teens. An Executive Summary of Adolescent Development Research Reviews Completed for the John S. and James L. Knight Foundation. Jonathan F. Zaff, Ph.D. and Kristin A. Moore, Ph.D. October 2002

[7] Susan Wile Schwarz. Adolescent mental health in the United States [internet]. 2009 [ cited Nov 21]. Available from: http://www.nccp.org/publications/pdf/text_878.pdf
[8] Kathieem Mullan Harris, Rasalind Berkowitz King, Penny Gordon-Larsen. Healthy habits among adolescents: Sleep, exercise, diet, and body image [internet].2003 [ cited 2011 Nov 12]. Availablefrom:http://www.childtrends.org/Files/Child_Trends-2003-03-12PD_PDConfHKGL.pdf

[9] Russell Vinar, Aidan Macfarlane. Health promotion [internet].2005 [ cited Nov 18]. Available from: http://www.ncbi.nlm.nih Gov/pmc/articles/PMC552817

[10] Zoe AK Walker, Joy Townsend. The role of general practice in promoting teenage health: a review of literature. Oxford journal. 1998 Jan 26; volume16, issue 2: p164-172.

[11] Waris Qidwai, Sidra Ishaque, Sabeen Shah, Maheen Rahi. Adolscent life style and behavior : A Survey from a Developing Country [ internet]. 2010[cited Oct 11]. Available from: http://www.plosone.org/article/info:doi\%2F10.1371\%2Fjournal.pone.00129

[12] Santrock, J. W. (2004). Life-span development (9th ed.). New York McGraw-Hill.

[13] Guiding Principles For Promoting Adolescents Health [internet]. Available from: http://health.mo.gov/linving/familes/adolescenthealth/pdf/Guiding PrinciplesForpromotingadolescenthealth.pdf

\section{AUTHORS}

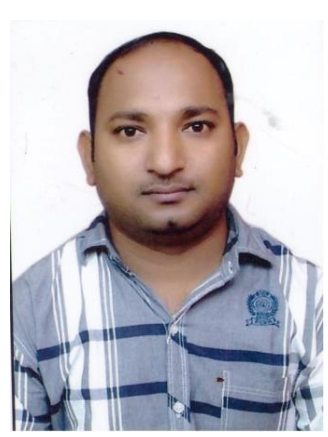

First Author - Mr. Kalpesh Kumar, PH.D. Scholar (Maharaja Vinayaka Global University Jaipur ), M.Sc. Nursing( Medical -Surgical Nursing), Principal ,Vidhyadeep Institute of Nursing , Anita (Kim ), Dist -Surat (Gujarat) 394110 Email Id - Jainkalpesh.kp@gmail.com

Research Guide :Dr. (Prof.)K.C.Yadav, Maharaja Vinayaka Global University , jaipur 